OPEN ACCESS

Edited by:

Thai Tran,

National University of Singapore,

Singapore

Reviewed by:

Patrick Lajoie,

University of Western Ontario, Canada

Christopher Auger,

Sunnybrook Health Sciences Centre,

Canada

${ }^{*}$ Correspondence:

Gary C. Sieck

sieck.gary@mayo.edu

Specialty section:

This article was submitted to

Molecular Medicine,

a section of the journal

Frontiers in Cell and Developmental

Biology

Received: 01 November 2019

Accepted: 16 December 2019

Published: 15 January 2020

Citation:

Delmotte P and Sieck GC (2020)

Endoplasmic Reticulum Stress and Mitochondrial Function in Airway

Smooth Muscle.

Front. Cell Dev. Biol. 7:374.

doi: 10.3389/fcell.2019.00374

\section{Endoplasmic Reticulum Stress and Mitochondrial Function in Airway Smooth Muscle}

\author{
Philippe Delmotte and Gary C. Sieck* \\ Department of Physiology and Biomedical Engineering, Mayo Clinic, Rochester, MN, United States
}

Inflammatory airway diseases such as asthma affect more than 300 million people worldwide. Inflammation triggers pathophysiology via such as tumor necrosis factor $\alpha$ (TNF $\alpha$ ) and interleukins (e.g., IL-13). Hypercontraction of airway smooth muscle (ASM) and ASM cell proliferation are major contributors to the exaggerated airway narrowing that occurs during agonist stimulation. An emergent theme in this context is the role of inflammationinduced endoplasmic reticulum (ER) stress and altered mitochondrial function including an increase in the formation of reactive oxygen species (ROS). This may establish a vicious cycle as excess ROS generation leads to further ER stress. Yet, it is unclear whether inflammation-induced ROS is the major mechanism leading to ER stress or the consequence of ER stress. In various diseases, inflammation leads to an increase in mitochondrial fission (fragmentation), associated with reduced levels of mitochondrial fusion proteins, such as mitofusin 2 (Mfn2). Mitochondrial fragmentation may be a homeostatic response since it is generally coupled with mitochondrial biogenesis and mitochondrial volume density thereby reducing demand on individual mitochondrion. ER stress is triggered by the accumulation of unfolded proteins, which induces a homeostatic response to alter protein balance via effects on protein synthesis and degradation. In addition, the ER stress response promotes protein folding via increased expression of molecular chaperone proteins. Reduced Mfn2 and altered mitochondrial dynamics may not only be downstream to ER stress but also upstream such that a reduction in Mfn2 triggers further ER stress. In this review, we summarize the current understanding of the link between inflammation-induced ER stress and mitochondrial function and the role played in the pathophysiology of inflammatory airway diseases.

Keywords: mitofusin, IRE1, XBP1, asthma, inflammation

\section{INTRODUCTION}

Inflammation triggers asthma pathophysiology via pro-inflammatory cytokines such as tumor necrosis factor $\alpha(\mathrm{TNF} \alpha)$ and interleukin 13 (IL-13). Two hallmarks of asthma are human airway smooth muscle (hASM) hypercontractility and cell proliferation (James, 2005; Joubert and Hamid, 2005; Black et al., 2012; Prakash, 2013, 2016; Wright et al., 2013a,b; Delmotte and Sieck, 2015). It is likely that with asthma, hASM exists in both hyper-contractile and proliferative states, thus contributing to a thicker, more contractile airway. An emergent theme in this context is the role of inflammation-induced endoplasmic reticulum (ER) stress and mitochondria. Previously, 
we showed that cytokine exposure increases agonist-induced hASM force and ATP consumption due to an increase in contractile protein expression (Dogan et al., 2017). Initially, the increase in hASM ATP demand is met by increased mitochondrial $\mathrm{O}_{2}$ consumption and ATP production, but at the expense of reactive oxygen species (ROS) formation and oxidative stress. There is increasing evidence that mitochondria and the ER, although structurally separate organelles, are functionally interdependent units, which must establish links for normal cellular function, including $\left[\mathrm{Ca}^{2+}\right]_{\mathrm{cyt}}$ regulation, energy production and cell proliferation (Hajnoczky et al., 2000; Franzini-Armstrong, 2007; Romagnoli et al., 2007; Liesa et al., 2009; Kornmann and Walter, 2010; Antico Arciuch et al., 2012; Glancy and Balaban, 2012; Dorn and Maack, 2013; Kornmann, 2013; Raturi and Simmen, 2013; van Vliet et al., 2014; Filadi et al., 2017). These links are established through specialized ER-mitochondria encounter structures (ERMES) comprising both ER and mitochondrial transmembrane proteins that provide a tethering force between the two organelles to ensure proximity and communication (Franzini-Armstrong, 2007; Kornmann and Walter, 2010; Dorn and Maack, 2013; Kornmann, 2013; Raturi and Simmen, 2013; van Vliet et al., 2014; Filadi et al., 2017). Mitofusin-2 (Mfn2) is an ERMES component that serves to tether mitochondria to the ER. Mfn2 also serves to fuse mitochondria, which together with other fusion proteins [e.g., Mfn1, optic atrophy 1 (Opa1)] elongate mitochondria making them more filamentous, whereas fission proteins such as dynamin related protein 1 (Drp1) and fission 1 protein (Fis1) act to fragment mitochondria. Together these fusion/fission proteins act to dynamically remodel mitochondria under a variety of conditions (Smirnova et al., 2001; James et al., 2003; Lee et al., 2004; Song et al., 2009; Sheridan and Martin, 2010; Palmer et al., 2011; Ranieri et al., 2013). The tethering of mitochondria to the ER allows mitochondrial proximity to $\mathrm{ER} \mathrm{Ca}^{2+}$ release sites representing a microdomain of higher $\left[\mathrm{Ca}^{2+}\right]_{c y t}$ ("hotspot" $>2 \mu \mathrm{M}$ ) that is essential for mitochondrial $\mathrm{Ca}^{2+}$ influx [by activating the mitochondrial $\mathrm{Ca}^{2+}$ uniporter (MCU)] (Raffaello et al., 2012). In the absence of mitochondrial $\mathrm{Ca}^{2+}$ buffering, the transient $\left[\mathrm{Ca}^{2+}\right]_{\text {cyt }}$ response to agonist stimulation is elevated, thereby enhancing hASM force generation. This review will discuss the link between ER stress, Mfn2 expression, mitochondrial tethering to the ER, mitochondrial $\mathrm{Ca}^{2+}$ influx, and mitochondrial function in the context of airway inflammation and potential consequences on ASM hyper-contractile and proliferative states.

\section{INFLAMMATION AND ER STRESS IN HUMAN ASM}

One consequence of inflammation is the unfolding of proteins that accumulate in the lumen of the ER, exposing binding sites for the chaperone protein, binding immunoglobulin protein (BiP). With an accumulation of unfolded proteins, BiP dissociates from three proteins localized at the ER membrane resulting in their activation. The resulting physiological response referred as ER stress or unfolded protein response attempts to restore normal
ER function by increasing chaperones proteins expression, halting protein translation and activating protein degradation (Yoshida et al., 2001; Bravo et al., 2012; Garg et al., 2012; Verfaillie et al., 2012; Hasnain et al., 2013; Sano and Reed, 2013; Vannuvel et al., 2013; Delmotte and Sieck, 2015; Kim and Lee, 2015; Zeeshan et al., 2016; Jeong et al., 2017; Navid and Colbert, 2017; Shanahan and Furmanik, 2017; Morris et al., 2018). These three ER stress protein markers involved in this signaling cascade are: protein kinase RNA-like ER kinase (PERK), activating transcription factor 6 (ATF6), and inositolrequiring enzyme 1 (IRE1 $\alpha$, also called serine/threonine-protein kinase/endoribonuclease IRE1 $\alpha$ ) (Figure 1) (Hai et al., 1989; Nikawa and Yamashita, 1992; Cox et al., 1993; Harding et al., 1999; Li et al., 2000). Phosphorylation of IRE1 $\alpha$ (pIRE1 $\alpha$ ) catalyzes the alternative splicing of XBP1 mRNA (XBP1s) and expression of the active XBP1s transcription factor. Generally, the pIRE1 $\alpha / \mathrm{XBP} 1 \mathrm{~s}$ pathway is associated with upregulation of chaperone protein expression that serves to promote protein refolding and restore ER homeostasis. The RNAse activity of IRE1 $\alpha$ is also involved in the regulation of mRNAs through a mechanism called regulated IRE1-dependent decay of mRNA (RIDD) (Hollien and Weissman, 2006). Interestingly, IRE1 $\alpha$ could also cleave several pre-miRNAs which could potentially regulate a number of mRNA targets (Upton et al., 2012). As a result, RIDD and therefore, ER stress could affect directly and indirectly a large number of mRNA targets. ATF6 translocates to the Golgi apparatus and is cleaved first by site 1 protease (S1P) and second by site 2 protease (S2P) leading to an active ATF6 transcription factor. As for the $\mathrm{pIRE} 1 \alpha / \mathrm{XBP} 1 \mathrm{~s}$ pathway, the ATF6 pathway is usually associated with upregulation of chaperone protein expression but also with autophagy, lipid synthesis and endoplasmic-reticulum-associated protein degradation (ERAD) (Yoshida et al., 2001; Bravo et al., 2012; Garg et al., 2012;

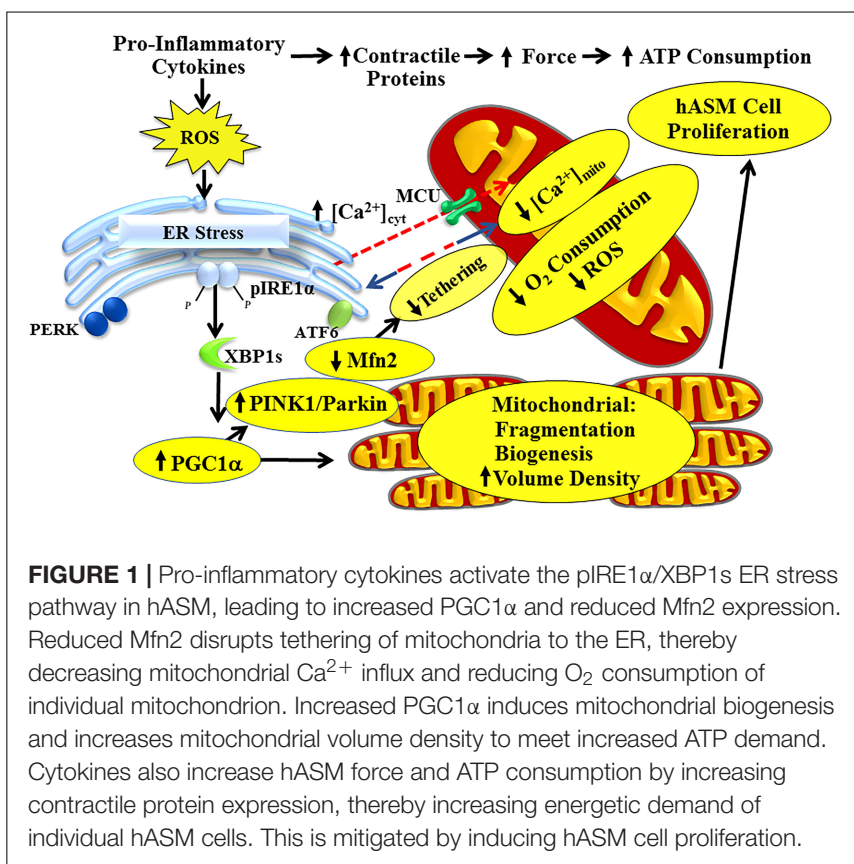


Verfaillie et al., 2012; Hasnain et al., 2013; Sano and Reed, 2013; Vannuvel et al., 2013; Delmotte and Sieck, 2015; Kim and Lee, 2015; Zeeshan et al., 2016; Jeong et al., 2017; Navid and Colbert, 2017; Shanahan and Furmanik, 2017; Morris et al., 2018). The role of ATF6 in the upregulation of XBP1 and the transcription factor C/EBP homologous protein (CHOP, ER stress-induced apoptosis) is also well documented and reviewed in $\mathrm{Hu}$ et al. (2018). Finally, PERK phosphorylates the translationinitiator factor eukaryotic initiation factor 2 (eIF2 $\alpha$ ), resulting in the translation of activating transcription factor 4 (ATF4). ATF4 is involved in the upregulation of CHOP, ERAD and mitophagy pathways (Adolph et al., 2012; Hasnain et al., 2012, 2013; Dromparis et al., 2013; Kim and Lee, 2015; Zeeshan et al., 2016; Jeong et al., 2017; Navid and Colbert, 2017; Shanahan and Furmanik, 2017; Hu et al., 2018; Morris et al., 2018). In cell types other than hASM, inflammation has been shown to induce ER stress (Adolph et al., 2012; Garg et al., 2012; Hasnain et al., 2012, 2013; Baban et al., 2013; Martino et al., 2013). These studies also demonstrated that the ER stress response is highly variable depending on cell type, species and experimental condition, which subsequently leads to various downstream physiological effects. Inflammation-induced ER stress is most likely a consequence of increased ROS generation (Adolph et al., 2012; Garg et al., 2012; Hasnain et al., 2012, 2013; Baban et al., 2013; Martino et al., 2013), although it is unclear whether ROS is the only mechanism involved. In a recent study, we showed that, $\mathrm{TNF} \alpha$ selectively activates the pIRE $1 \alpha / \mathrm{XBP} 1 \mathrm{~s}$ in non-asthmatic hASM cells (Yap et al., 2019). Whether cytokines other than $\mathrm{TNF} \alpha$ also selectively activate the pIRE $1 \alpha / \mathrm{XBP} 1$ s pathway is not known. Interestingly, $\mathrm{TNF} \alpha$ increases superoxide formation in hASM and Tempol, a superoxide scavenger, reduces the effect of TNF $\alpha$ on the activation of PIRE $1 \alpha / \mathrm{XBP} 1$ s pathway (Yap et al., 2019). To date no other study has explored whether inflammation induces ER stress in hASM and whether an ER stress response in hASM cells from asthmatic patients exists and/or is affected by inflammation. A few studies suggest that the ER stress response is exaggerated in airway epithelial cells or immune cells in the context of asthma (Kim and Lee, 2015; Jeong et al., 2017; Pathinayake et al., 2018). In a mouse model of asthma, chemical chaperones have been used to reduce the ER stress response and attenuate airway hyperresponsiveness (Makhija et al., 2014; Miller et al., 2014; Kim and Lee, 2015; Siddesha et al., 2016).

\section{Mfn2 AND ER STRESS RESPONSE}

In cells other than hASM, the relationship between the ER stress response and mitochondria has gain considerable interest. These previous studies have suggested that Mfn2 and altered mitochondrial dynamics are upstream to ER stress such that a reduction in Mfn2 triggers ER stress (Munoz and Zorzano, 2011; Ngoh et al., 2012; Schneeberger et al., 2013; Bhandari et al., 2015). In a recent study, we suggested that a reduction in Mfn2 in hASM cells is downstream to ER stress (Yap et al., 2019), creating the possibility of a vicious cycle with reduced Mfn2 expression and altered mitochondrial function at the center. Currently, the link between ER stress and downstream regulation of Mfn2 expression has been largely unexplored. A limited number of studies have examined specific downstream targets of activation of the pIRE1 $\alpha / \mathrm{XBP} 1$ s pathway (Calfon et al., 2002; Fonseca et al., 2005; Lipson et al., 2006, 2008; Zeng et al., 2009), but none of these studies have examined effects on Mfn2 expression. As mentioned above, TNF $\alpha$ selectively activates the pIRE1 $\alpha / \mathrm{XBP} 1 \mathrm{~s}$ pathway and reduces Mfn2 expression (Yap et al., 2019), but how IRE1 $\alpha$ phosphorylation and XBP1 mRNA splicing affects Mfn2 expression has not been examined in any cell type. Potential targets of interest include peroxisome proliferator-activated receptor gamma coactivator 1-alpha (PGC1 $\alpha$ ), mitophagyrelated proteins PTEN-induced kinase 1 (PINK1) and Parkin, and miRNAs (Figure 1). Several studies found that XBP1s increases expression of PGC1 $\alpha$ (Arensdorf et al., 2013; Cheang et al., 2017). Interestingly, PGC1 $\alpha$ activates the PINK1/Parkin mitophagy pathway, which is involved in ubiquitination of Mfn2 (Chen and Dorn, 2013; Basso et al., 2018; McLelland et al., 2018). Similarly, a growing list of miRNA has been implicated in the downregulation of Mfn2 but it is not clear if they are expressed in hASM and whether XBP1 is involved in their regulation (Kuhn et al., 2010; Dileepan et al., 2016; Purohit et al., 2019). Previous studies have also shown that XBP1 induces several miRNA but their potential effect on Mfn2 has not been explored and again it's not known if these miRNA are expressed in hASM (Kuhn et al., 2010; Dileepan et al., 2016; Purohit et al., 2019). The PERK and ATF6 pathway have also been suggested to affect Mfn2 expression, either through PGC1 $\alpha$, mitophagy or ERAD pathways (Morris et al., 2018). It is not known if cytokines other than TNF $\alpha$ activate the PERK and ATF6 pathway in hASM and whether they are activated or amplified in asthmatic hASM. Conversely, the effect of Mfn2 knockdown on IRE1 $\alpha$ phosphorylation and XBP1 mRNA splicing has only been examined by four studies - two in neurons, and one each in embryonic fibroblasts and Drosophila (Ngoh et al., 2012; Munoz et al., 2013; Schneeberger et al., 2013; Bhandari et al., 2015).

\section{Mfn2 AND DYNAMIC REMODELING OF MITOCHONDRIA}

In hASM, mitochondria are tubular or filamentous but this mitochondria morphology is highly dynamic with mitochondria constantly fusing (fusion) or breaking (fission) from one another. Mitochondria morphology is therefore, the result of this balance between fusion vs. fission (Chen and Chan, 2005; Chan, 2006, 2012; Liesa et al., 2009; Youle and van der Bliek, 2012). This dynamic remodeling is thought to be essential for mitochondrial DNA stability, respiratory function, and to adapt cellular stress resulting from ROS formation (Chan, 2012). Mitochondrial fusion involves the GTPases Mfn1 and/or Mfn2 responsible for the fusion of the outer membrane, and optic atrophy protein 1 (OPA1) for the fusion of the mitochondrial inner membrane (Figure 2). Mfn1 is located only at the mitochondrial outer membrane whereas Mfn2 is localized both at the mitochondrial membrane and in the cytosol. The dimerization of Mfn2 (Mfn2/Mfn2) and/or Mfn1 (Mfn1/Mfn2) tethers outer membranes of neighboring mitochondria (Song et al., 2009; 


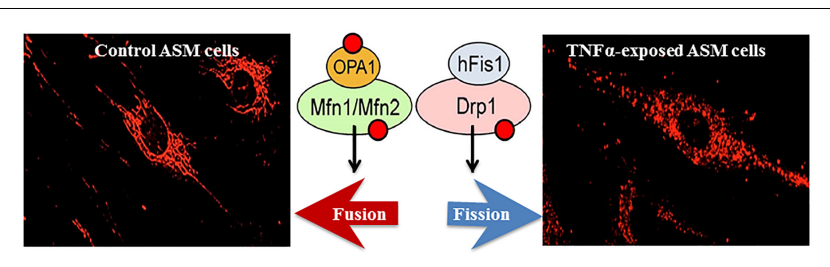

FIGURE 2 | In hASM, TNF $\alpha$ increases mitochondrial fragmentation (fission, visualized using MitoTracker Red); an effect mediated through a reduced expression of fusion proteins (Mfn2, Mfn1, and Opa1) and an increased expression of fission proteins (Drp1 and hFis1).

Palmer et al., 2011; Ranieri et al., 2013). Mitochondrial fission depends on the recruitment of cytosolic Drp1 by Fis1 to specific positions around mitochondria and known as constriction sites ultimately leading to fragmentation/fission of the mitochondria (Smirnova et al., 2001; James et al., 2003; Lee et al., 2004; Sheridan and Martin, 2010). The extent of fusion or fission of mitochondria can be quantified using morphological parameters such as form factor (perimeter $2 / 4 \pi \times$ area) and/or aspect ratio (ratio of long and short axis) (Koopman et al., 2005a,b, 2006). We previously reported that Mfn2 expression was reduced in asthmatic hASM, and that this was correlated with an increase in mitochondria fragmentation (Aravamudan et al., 2014). A similar increase in mitochondrial fragmentation in hASM cells was observed after siRNA knockdown of Mfn2 (Aravamudan et al., 2017). In a recent study, we also found that $\mathrm{TNF} \alpha$ reduces Mfn2 expression in hASM cells (Yap et al., 2019). As mentioned before, the relation between ER stress and Mfn2 expression and mitochondria fragmentation has been suggested but has not been clearly established.

\section{ROLE OF Mfn2 IN TETHERING MITOCHONDRIA TO ER}

There is converging evidence in other cell types that Mfn2 plays an essential role in tethering mitochondria to the ER (Hajnoczky et al., 2002; Patergnani et al., 2011; Raturi and Simmen, 2013; van Vliet et al., 2014; Filadi et al., 2017). Mfn2 located at the ER membrane can dimerize with Mfn2 (Mfn2/Mfn2) and/or Mfn1 (Mfn1/Mfn2) located at the mitochondrial membrane to tether mitochondria to the ER. In hASM cells, a transient $\left[\mathrm{Ca}^{2+}\right]_{\text {cyt }}$ response induced by $1 \mu \mathrm{M}$ ACh stimulation is accompanied by a transient $\left[\mathrm{Ca}^{2+}\right]_{\text {mito }}$ response (Delmotte et al., 2012; Delmotte and Sieck, 2015). The transient $\left[\mathrm{Ca}^{2+}\right]_{\text {mito }}$ response is blunted by inhibiting the MCU using Ru360. Mitochondrial $\mathrm{Ca}^{2+}$ influx via the MCU (Baughman et al., 2011; De Stefani et al., 2011) is only activated by microdomains of higher $\left[\mathrm{Ca}^{2+}\right]_{c y t}$ ("hotspots" > $2 \mu \mathrm{M}$ ) (Gunter et al., 2000; Gunter and Gunter, 2001; Rizzuto and Pozzan, 2006; Gunter and Sheu, 2009; Rizzuto et al., 2009; Giacomello et al., 2010), which exceed the normal global transient $\left[\mathrm{Ca}^{2+}\right]_{\text {cyt }}$ response to agonist stimulation in hASM ( 500-600 nM) (Pabelick et al., 1999; Sieck et al., 2008; Sathish et al., 2009, 2011; Delmotte et al., 2012). Higher levels of $\left[\mathrm{Ca}^{2+}\right]_{\text {cyt }}$ do occur after $24-\mathrm{h} \mathrm{TNF} \alpha$ exposure in response to muscarinic stimulation (Delmotte et al., 2012; Delmotte and Sieck, 2015; Dogan et al., 2017; Sieck et al., 2019), but are still well below levels required to activate the MCU (Gunter et al., 2000; Gunter and Gunter, 2001; Rizzuto and Pozzan, 2006; Gunter and Sheu, 2009; Rizzuto et al., 2009; Giacomello et al., 2010). However, much higher levels of $\left[\mathrm{Ca}^{2+}\right]_{\text {cyt }}$ ("hotspots") are observed in regions in close proximity to the $\mathrm{ER} \mathrm{Ca}^{2+}$ efflux channels $\left(\mathrm{IP}_{3}\right.$ and RyR). Thus, during agonist stimulation, mitochondria must be tethered to the ER in order to establish close proximity of mitochondria to $\left[\mathrm{Ca}^{2+}\right]_{\text {cyt }}$ "hotspots" for mitochondrial $\mathrm{Ca}^{2+}$ influx. We previously showed that TNF $\alpha$ disrupts mitochondrial proximity to the ER in hASM cells (Delmotte et al., 2017), but this study only suggests the potential involvement of reduced Mfn2 expression in hASM. Further studies will be necessary to provide direct evidence for the involvement of Mfn2. In hASM cells, it has not been established that Mfn2 is essential for tethering mitochondria to the ER, and thus, for establishing proximity of mitochondria to the ER and microdomains of higher $\left[\mathrm{Ca}^{2+}\right]_{\text {cyt }}$ ("hotspots" $>2 \mu \mathrm{M}$ ). Such interactions are cell and context specific, so establishing the role of Mfn2 in hASM is critical. The potential effect of ER stress on microdomains of higher $\left[\mathrm{Ca}^{2+}\right]_{c y t}$, and mitochondrial $\mathrm{Ca}^{2+}$ influx is likewise not clearly established.

\section{EXCITATION-ENERGY COUPLING VIA MITOCHONDRIAL Ca ${ }^{2+}$ INFLUX}

Based on biochemical studies, it is well known that mitochondrial production of ATP (oxidative phosphorylation) depends on dehydrogenase enzyme activities of the tricarboxylic acid (TCA) cycle (or citric acid cycle). Some of these dehydrogenase enzymes [i.e., pyruvate dehydrogenase (PDH), NAD-isocitrate dehydrogenase (ICDH), and oxoglutarate dehydrogenase (OGDH)] are $\mathrm{Ca}^{2+}$ dependent (Rizzuto et al., 2000; Parekh, 2003; Franzini-Armstrong, 2007; Maack and O'Rourke, 2007; Romagnoli et al., 2007). Additionally, an increase in $\left[\mathrm{Ca}^{2+}\right]_{\text {cyt }}$ stimulates mitochondrial shuttle systems such as the glycerol phosphate shuttle and the aspartate/glutamate transporters resulting in an increase in $\mathrm{NADH}$ levels in the mitochondria (Palmieri et al., 2001; Denton, 2009). Thus, mitochondrial $\mathrm{Ca}^{2+}$ influx during transient elevation of $\left[\mathrm{Ca}^{2+}\right]_{\text {cyt }}$ stimulates dehydrogenase enzyme activities within the TCA cycle and increases, $\mathrm{O}_{2}$ consumption, electron transport chain (ETC) flux and ATP production - excitation-energy coupling (Figure 3). Conversely, it is well known that increased ATP consumption leads to transport of ADP into mitochondria via the adenosine nucleotide transporter (ANT), which stimulates ATP synthase (complex V) activity to match ATP production with ATP consumption (Figure 3). Together, these two energy sensing pathways form a normal homeostatic mechanism for excitationenergy coupling in a variety of cell types including hASM. Pathophysiology and mitochondrial dysfunction involve disruptions in these mitochondrial energy-sensing/signaling pathways. As mentioned, most of these studies involved biochemical studies and in some cases isolated mitochondria. While they are critical in our understanding of mitochondrial 


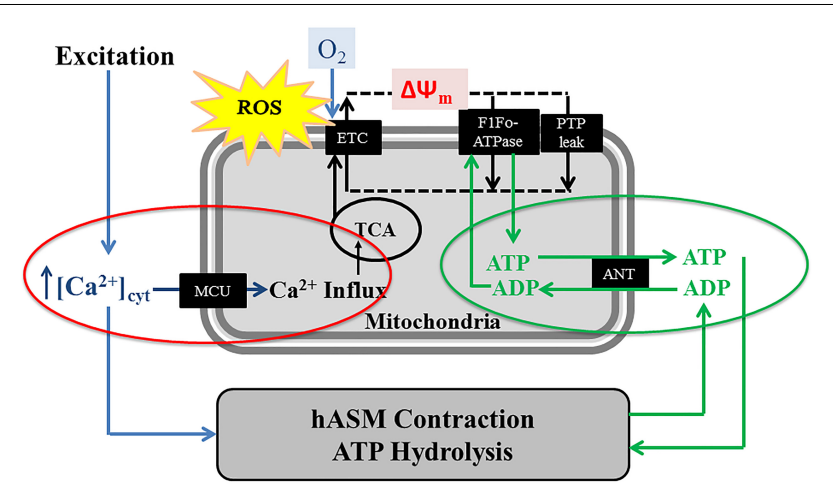

FIGURE 3 | In hASM cells, the agonist-induced transient increase of $\left[\mathrm{Ca}^{2+}\right]_{\text {cyt }}$ (excitation) is accompanied by activation of the mitochondrial $\mathrm{Ca}^{2+}$ uniporter (MCU) and a transient increase in mitochondrial $\mathrm{Ca}^{2+}$ influx, thereby increasing activities of mitochondrial dehydrogenases of the TCA cycle and the electron transport chain (ETC). Mitochondrial $\mathrm{O}_{2}$ consumption and ATP synthesis are also linked ATP hydrolysis (and therefore, hASM force) via changes in the ATP/ADP ratio and the adenine nucleotide transporter (ANT). A portion of the $\mathrm{O}_{2}$ consumed in the ETC results in ROS formation.

function, there's a considerable need for new tools allowing to studies these mechanisms within single mitochondrion in live cells and tissues. A few imaging and/or molecular tools to measure mitochondrial membrane potential $\Delta \Psi_{\mathrm{m}}$, succinate dehydrogenase (SDH) activity (Sieck et al., 1986, 1989, 1995, 1996), ATP consumption (Jones et al., 1999a,b; Dogan et al., 2017), ATP/ADP (Berg et al., 2009), and NAD/NADH ratio (Hung et al., 2011; Cohen et al., 2018) have been developed for use in live cells or tissue but have never been used in hASM.

\section{ROLE OF ER STRESS IN MITOCHONDRIAL BIOGENESIS AND INCREASED MITOCHONDRIAL VOLUME DENSITY}

A few studies reported that mitochondrial biogenesis in asthmatic hASM is increased but the mechanisms mediating this mitochondrial biogenesis were not explored (Trian et al., 2007; Girodet et al., 2011). These studies also did not examine mitochondria morphology and mitochondrial fragmentation/fission. An increase in mitochondrial volume density is an alternative mechanism to increase ATP production to meet increased ATP demand in hASM after exposure to pro-inflammatory cytokines. In this case, $\mathrm{O}_{2}$ consumption in individual mitochondrion can be reduced to minimize formation of ROS. Recent evidence also suggests that reduced Mfn2 and mitochondrial fragmentation is required for mitochondrial biogenesis (Antico Arciuch et al., 2012; Peng et al., 2017), supporting our hypothesis that increased PGC1 $\alpha$ and reduced Mfn2 are a coordinated homeostatic response to cytokine-induced activation of the $\mathrm{pIRE} 1 \alpha / \mathrm{XBP} 1 \mathrm{~s}$ ER stress pathway.

\section{CYTOKINE EXPOSURE INCREASES ROS GENERATION IN hASM}

A number of studies have reported that ROS generation increases in asthmatic patients (Katsumata et al., 1990; Comhair and Erzurum, 2010; Zuo et al., 2013) which has the potential to triggers ER stress in hASM. We recently showed exposure of nonasthmatic hASM to TNF $\alpha$ progressively increases superoxide anion formation (Yap et al., 2019). We also found that incubating hASM cells with Tempol (superoxide anion scavenger) mitigated the effects of TNF $\alpha$ in inducing ER stress as well as the reduction in Mfn2 (Yap et al., 2019). It is possible that an increase in ROS generation is triggered, in part by increased ATP consumption and mitochondrial $\mathrm{O}_{2}$ consumption. Acute activation of the pIRE1 $\alpha / \mathrm{XBP} 1 s$ ER stress pathway leads to a transient reduction in Mfn2 thereby decreasing: (1) mitochondrial tethering to the ER (Figure 1); (2) mitochondrial $\mathrm{Ca}^{2+}$ influx (Figures 1, 3); (3) TCA cycle dehydrogenase enzyme activity (Figures 1, 3); (4) $\mathrm{O}_{2}$ consumption (Figures 1, 3); and as a result, (5) ROS formation (Figures 1, 3). Without this homeostatic break on mitochondrial $\mathrm{O}_{2}$ consumption, the increase in hASM force and ATP consumption induced by pro-inflammatory cytokines will increase ROS formation and further exacerbating ER stress.

\section{CYTOKINE EXPOSURE INCREASES hASM FORCE, ATP CONSUMPTION AND TENSION COST}

In previous studies, we showed that 24-h exposure of hASM cells to $\mathrm{TNF} \alpha$ increases both $\left[\mathrm{Ca}^{2+}\right]_{\text {cyt }}$ and force responses to $1 \mu \mathrm{M}$ muscarinic (ACh) stimulation (White et al., 2006; Sathish et al., 2009, 2011; Delmotte et al., 2012; Jia et al., 2013; Delmotte and Sieck, 2015; Dogan et al., 2017; Sieck et al., 2019). However, hASM sensitivity to muscarinic stimulation is also increased after $\mathrm{TNF} \alpha$, which largely accounts for the enhanced $\left[\mathrm{Ca}^{2+}\right]_{\text {cyt }}$ response, but not the force response (Sieck et al., 2019). In recent studies, we found that the increase in ASM force induced by $24-\mathrm{h} \mathrm{TNF} \alpha$ exposure is due to an increase in contractile protein expression (Dogan et al., 2017; Sieck et al., 2019). Importantly, the increase in hASM force generation induced by $\mathrm{TNF} \alpha$ exposure is associated with an increase in ATP consumption and tension cost (Dogan et al., 2017). This study used an NADH-linked fluorescence technique in permeabilized hASM in which the level of $\mathrm{Ca}^{2+}$ activation and force generation can be controlled. In previous studies, we showed that in ASM force generation is directly related to ATP hydrolysis rate (Jones et al., 1999a,b; Dogan et al., 2017). During isometric activation of hASM, ATP hydrolysis rate is initially faster and then declines with time to a sustained level even though isometric force is maintained (the "latch" state). Thus, there is a time-dependent decline in both ATP hydrolysis rate and tension cost that is likely due to cytoskeletal remodeling (Jones et al., 1999b). When actin polymerization in hASM is inhibited, force decreases while ATP hydrolysis rate increases; thereby increasing tension cost (Jones et al., 1999a,b). Normally, 
tension cost of hASM is dramatically lower than skeletal muscle, but work efficiency is remarkably high (Sieck et al., 1998). Thus, the energetics of hASM are perfectly suited to sustain force at low energy cost. In hASM cells, an increase in ATP consumption is met by stimulation of ATP synthase activity (complex V) and an increase in $\mathrm{O}_{2}$ consumption and ATP production (Figures 1, 3). However, stimulation of mitochondrial $\mathrm{O}_{2}$ consumption results in increased ROS formation that can trigger protein unfolding and an ER stress response. Thus, we propose that the pIRE1 $\alpha / \mathrm{XBP} 1 \mathrm{~s}$ ER stress pathway represents a homeostatic response directed toward reducing $\mathrm{O}_{2}$ consumption and ROS formation in an individual mitochondrion, while increasing mitochondrial biogenesis and mitochondrial volume density to meet the increase in ATP demand. This leads to the question of how energy demand and supply are matched with continued exposure to pro-inflammatory cytokines. Sustained contractility at reduced tension cost is a hallmark of smooth muscle function, and any perturbation should be met with a homeostatic response. One possibility is that hASM cell proliferation (hyperplasia response) provides a mechanism to maintain contractility but at reduced ATP cost per cell.

\section{ROLE OF Mfn2 IN hASM CELL PROLIFERATION}

Recent evidence suggests that Mfn2 affects several proproliferative pathways and that dynamic mitochondrial remodeling (balance between fusion and fragmentation/fission) governs cell proliferation (Liesa et al., 2009; Antico Arciuch et al., 2012). During cell division, the number of mitochondria or therefore mitochondrial biogenesis needs to increase so each subsequent cell has a similar number of mitochondria (Antico Arciuch et al., 2012). As a result, mitochondria fuse then fragment to generate more mitochondria. Two studies in vascular smooth muscle show that Mfn2 is critical in cell division (Liesa et al., 2009; Antico Arciuch et al., 2012). Notably, the authors show that Mfn2 interacts with several pro-proliferative kinases such as extracellular signal-regulated kinase (ERK1/2) and participates in their inactivation (Liesa et al., 2009; Antico Arciuch et al., 2012). As a result, overexpression of Mfn2 in vascular smooth muscle inhibits cell proliferation (Liesa et al., 2009; Antico Arciuch et al., 2012). Importantly, ERK1/2 activation is believed to play a critical role in hASM proliferation induced by inflammatory cytokines (Lee et al., 2001; Kip et al., 2005; Yu et al., 2013; Dragon et al., 2014; Movassagh et al., 2014). While the relation between ER stress and Mfn2 is not clearly established, studies suggest that ER stress induces cell proliferation in many cell types (Vandewynckel et al., 2013; Chen et al., 2018). Whether ER stress induces hASM cell proliferation is unknown.

\section{THERAPEUTIC APPROACHES TARGETING ER STRESS}

An increase in ROS generation is likely responsible for inflammation-induced ER stress. Based on increased ROS generation associated with asthma, the benefits of antioxidant therapeutic have been explored (Heffner and Repine, 1989; Bast et al., 1991; Buhl et al., 1996; Jain and Chandel, 2013). However, one of the challenges with antioxidant treatment is specificity both in terms of ROS targeting and localization (extracellular, cytosol or mitochondrial). It is also now recognized that ROS regulate many cellular signaling cascades and have the potential to be more harmful than beneficial. An alternative therapeutic strategy of reducing ER stress in ASM is the use of chemical chaperone. Well tolerated even at high dose, chemical chaperones are effective in reducing ER stress in vivo. Bunezile, the US brand name for sodium phenylbutyrate or 4-phenylbutyrate (4PBA), is currently used for patients with urea cycle disorders. Chemical chaperones such 4-PBA or tauroursodeoxycholic acid (TUDCA) have gained considerable interest as a potential therapy for a number of other diseases including but not limited to cystic fibrosis [national clinical trial (NCT)00590538 for 4-PBA and NCT00004441 for TUDCA], amyotrophic lateral sclerosis (NCT00107770 for 4-PBA and NCT03800524 for TUDCA) and some types of cancer (NCT00006019 for 4-PBA). A recent phase 1 clinical trial for TUDCA in patients with asthma has been initiated (NCT03878654). Studies in mice showed that 4-PBA attenuated airway inflammation and also reduced airway hyperreactivity in mice model of asthma further indicating a promising therapeutic role for chemical chaperones in the pathogenesis of asthma (Hoffman et al., 2013; Kim et al., 2013; Makhija et al., 2014). The effect of 4-PBA or TUDCA on ASM were not examined and it's not clear how the chemical chaperone achieved its effect, further illustrating the need to better understand how inflammation induces ER stress in hASM.

\section{CONCLUSION AND PERSPECTIVES}

Inflammation, airway hyper-contractility and proliferative remodeling are key aspects of airways diseases such as asthma. The role of inflammation-induced ER stress with downstream impact on Mfn2 and mitochondrial function is of particular interest. The ER stress pathways have been implicated in a growing number of downstream effects ranging from cell death to cell survival. Mfn2 is involved in mitochondrial tethering to the $\mathrm{ER}$, mitochondrial $\mathrm{Ca}^{2+}$ influx, $\mathrm{O}_{2}$ consumption, and ROS formation. Surprisingly, ER stress and Mfn2 have been largely overlooked in hASM. Mitigation of inflammationinduced ER stress in hASM may represent a novel target for therapeutic intervention.

\section{AUTHOR CONTRIBUTIONS}

PD and GS wrote the manuscript.

\section{FUNDING}

This work was supported by the National Institutes of Health (NIH) RO1HL126451 and RO1HL150890 to GS. 


\section{REFERENCES}

Adolph, T. E., Niederreiter, L., Blumberg, R. S., and Kaser, A. (2012). Endoplasmic reticulum stress and inflammation. Dig. Dis. 30, 341-346. doi: 10.1159/ 000338121

Antico Arciuch, V. G., Elguero, M. E., Poderoso, J. J., and Carreras, M. C. (2012). Mitochondrial regulation of cell cycle and proliferation. Antioxid. Redox Signal. 16, 1150-1180. doi: 10.1089/ars.2011.4085

Aravamudan, B., Kiel, A., Freeman, M., Delmotte, P., Thompson, M., Vassallo, R., et al. (2014). Cigarette smoke-induced mitochondrial fragmentation and dysfunction in human airway smooth muscle. Am .J. Physiol. Lung. Cell Mol. Physiol. 306, L840-L854. doi: 10.1152/ajplung.00155.2013

Aravamudan, B., Thompson, M., Sieck, G. C., Vassallo, R., Pabelick, C. M., and Prakash, Y. S. (2017). Functional effects of cigarette smoke-induced changes in airway smooth muscle mitochondrial morphology. J. Cell Physiol. 232, 1053-1068. doi: 10.1002/jcp.25508

Arensdorf, A. M., Diedrichs, D., and Rutkowski, D. T. (2013). Regulation of the transcriptome by ER stress: non-canonical mechanisms and physiological consequences. Front. Genet. 4:256. doi: 10.3389/fgene.2013.00256

Baban, B., Liu, J. Y., and Mozaffari, M. S. (2013). Endoplasmic reticulum stress response and inflammatory cytokines in type 2 diabetic nephropathy: role of indoleamine 2,3-dioxygenase and programmed death-1. Exp. Mol. Pathol .94, 343-351. doi: 10.1016/j.yexmp.2012.11.004

Basso, V., Marchesan, E., Peggion, C., Chakraborty, J., von Stockum, S., Giacomello, M., et al. (2018). Regulation of ER-mitochondria contacts by Parkin via Mfn2. Pharmacol. Res 138, 43-56. doi: 10.1016/j.phrs.2018.09.006

Bast, A., Haenen, G. R., and Doelman, C. J. (1991). Oxidants and antioxidants: state of the art. Am. J. Med 91, 2S-13S. doi: 10.1016/0002-9343(91)90278-90276

Baughman, J. M., Perocchi, F., Girgis, H. S., Plovanich, M., Belcher-Timme, C. A., Sancak, Y., et al. (2011). Integrative genomics identifies MCU as an essential component of the mitochondrial calcium uniporter. Nature 476, 341-345. doi: 10.1038 /nature 10234

Berg, J., Hung, Y. P., and Yellen, G. (2009). A genetically encoded fluorescent reporter of ATP:ADP ratio. Nat. Methods 6, 161-166. doi: 10.1038/nmeth. 1288

Bhandari, P., Song, M., and Dorn, G. W. 2nd (2015). Dissociation of mitochondrial from sarcoplasmic reticular stress in Drosophila cardiomyopathy induced by molecularly distinct mitochondrial fusion defects. J. Mol. Cell Cardiol. 80, 71-80. doi: 10.1016/j.yjmcc.2014.12.018

Black, J. L., Panettieri, R. A. Jr., Banerjee, A., and Berger, P. (2012). Airway smooth muscle in asthma: just a target for bronchodilation? Clin. Chest. Med. 33, 543-558. doi: 10.1016/j.ccm.2012.05.002

Bravo, R., Gutierrez, T., Paredes, F., Gatica, D., Rodriguez, A. E., Pedrozo, Z., et al. (2012). Endoplasmic reticulum: ER stress regulates mitochondrial bioenergetics. Int. J. Biochem. Cell Biol. 44, 16-20. doi: 10.1016/j.biocel.2011. 10.012

Buhl, R., Meyer, A., and Vogelmeier, C. (1996). Oxidant-protease interaction in the lung. Prospects for antioxidant therapy. Chest 110(6 Suppl.), 267S-272S. doi: 10.1378/chest.110.6_supplement.267s

Calfon, M., Zeng, H., Urano, F., Till, J. H., Hubbard, S. R., Harding, H. P., et al. (2002). IRE1 couples endoplasmic reticulum load to secretory capacity by processing the XBP-1 mRNA. Nature 415, 92-96. doi: 10.1038/415092a

Chan, D. C. (2006). Mitochondrial fusion and fission in mammals. Annu. Rev. Cell Dev. Biol. 22, 79-99. doi: 10.1146/annurev.cellbio.22.010305.104638

Chan, D. C. (2012). Fusion and fission: interlinked processes critical for mitochondrial health. Annu. Rev. Genet. 46, 265-287. doi: 10.1146/annurevgenet-110410-132529

Cheang, W. S., Wong, W. T., Zhao, L., Xu, J., Wang, L., Lau, C. W., et al. (2017). PPARdelta Is required for exercise to attenuate endoplasmic reticulum stress and endothelial dysfunction in diabetic mice. Diabetes 66, 519-528. doi: 10. 2337/db15-1657

Chen, H., and Chan, D. C. (2005). Emerging functions of mammalian mitochondrial fusion and fission. Hum. Mol. Genet. 14, R283-R289. doi: 10. 1093/hmg/ddi270

Chen, L., Liu, L., Xie, Z. Y., Wang, F., Sinkemani, A., Zhang, C., et al. (2018). Endoplasmic reticulum stress facilitates the survival and proliferation of nucleus pulposus cells in TNF-alpha Stimulus by activating unfolded protein response. DNA Cell Biol. 37, 347-358. doi: 10.1089/dna.2017.4029
Chen, Y., and Dorn, G. W. II (2013). PINK1-phosphorylated mitofusin 2 is a Parkin receptor for culling damaged mitochondria. Science 340, 471-475. doi: 10.1126/science. 1231031

Cohen, M. S., Stewart, M. L., Goodman, R. H., and Cambronne, X. A. (2018). Methods for using a genetically encoded fluorescent biosensor to monitor nuclear NAD < sup/>. Methods Mol. Biol. 1813, 391-414. doi: 10.1007/978-14939-8588-3_26

Comhair, S. A., and Erzurum, S. C. (2010). Redox control of asthma: molecular mechanisms and therapeutic opportunities. Antioxid. Redox Signal. 12, 93-124. doi: 10.1089/ARS.2008.2425

Cox, J. S., Shamu, C. E., and Walter, P. (1993). Transcriptional induction of genes encoding endoplasmic reticulum resident proteins requires a transmembrane protein kinase. Cell 73, 1197-1206. doi: 10.1016/0092-8674(93)90648-a

De Stefani, D., Raffaello, A., Teardo, E., Szabo, I., and Rizzuto, R. (2011). A forty-kilodalton protein of the inner membrane is the mitochondrial calcium uniporter. Nature 476, 336-340. doi: 10.1038/nature10230

Delmotte, P., and Sieck, G. C. (2015). Interaction between endoplasmic/sarcoplasmic reticulum stress (ER/SR stress), mitochondrial signaling and $\mathrm{Ca}(2+)$ regulation in airway smooth muscle (ASM). Can. J. Physiol. Pharmacol. 93, 97-110. doi: 10.1139/cjpp-2014-2361

Delmotte, P., Yang, B., Thompson, M. A., Pabelick, C. M., Prakash, Y. S., and Sieck, G. C. (2012). Inflammation alters regional mitochondrial $\mathrm{Ca}(2)+$ in human airway smooth muscle cells. Am. J. Physiol. Cell Physiol. 303, C244-C256. doi: 10.1152/ajpcell.00414.2011

Delmotte, P., Zavaletta, V. A., Thompson, M. A., Prakash, Y. S., and Sieck, G. C. (2017). TNFalpha decreases mitochondrial movement in human airway smooth muscle. Am. J. Physiol. Lung. Cell Mol. Physiol. 313, L166-L176. doi: 10.1152/ ajplung.00538.2016

Denton, R. M. (2009). Regulation of mitochondrial dehydrogenases by calcium ions. Biochim. Biophys. Acta 1787, 1309-1316. doi: 10.1016/j.bbabio.2009. 01.005

Dileepan, M., Sarver, A. E., Rao, S. P., Panettieri, RA Jr, Subramanian, S., and Kannan, M. S. (2016). microrna mediated chemokine responses in human airway smooth muscle cells. PLoS One 11:e0150842. doi: 10.1371/journal.pone. 0150842

Dogan, M., Han, Y. S., Delmotte, P., and Sieck, G. C. (2017). TNFalpha enhances force generation in airway smooth muscle. Am. J. Physiol. Lung. Cell Mol. Physiol. 312, L994-L1002. doi: 10.1152/ajplung.00550.2016

Dorn, G. W. II, and Maack, C. (2013). SR and mitochondria: calcium cross-talk between kissing cousins. J. Mol. Cell Cardiol. 55, 42-49. doi: 10.1016/j.yjmcc. 2012.07.015

Dragon, S., Hirst, S. J., Lee, T. H., and Gounni, A. S. (2014). IL-17A mediates a selective gene expression profile in asthmatic human airway smooth muscle cells. Am. J. Respir. Cell Mol. Biol. 50, 1053-1063. doi: 10.1165/rcmb.20120267OC

Dromparis, P., Paulin, R., Stenson, T. H., Haromy, A., Sutendra, G., and Michelakis, E. D. (2013). Attenuating endoplasmic reticulum stress as a novel therapeutic strategy in pulmonary hypertension. Circulation 127, 115-125. doi: 10.1161/ CIRCULATIONAHA.112.133413

Filadi, R., Theurey, P., and Pizzo, P. (2017). The endoplasmic reticulummitochondria coupling in health and disease: molecules, functions and significance. Cell Calcium 62, 1-15. doi: 10.1016/j.ceca.2017.01.003

Fonseca, S. G., Fukuma, M., Lipson, K. L., Nguyen, L. X., Allen, J. R., Oka, Y., et al. (2005). WFS1 is a novel component of the unfolded protein response and maintains homeostasis of the endoplasmic reticulum in pancreatic beta-cells. J. Biol. Chem. 280, 39609-39615. doi: 10.1074/jbc.M507426200

Franzini-Armstrong, C. (2007). ER-mitochondria communication. How privileged? Physiology 22, 261-268. doi: 10.1152/physiol.00017.2007

Garg, A. D., Kaczmarek, A., Krysko, O., Vandenabeele, P., Krysko, D. V., and Agostinis, P. (2012). ER stress-induced inflammation: does it aid or impede disease progression? Trends Mol. Med. 18, 589-598. doi: 10.1016/j.molmed. 2012.06.010

Giacomello, M., Drago, I., Bortolozzi, M., Scorzeto, M., Gianelle, A., Pizzo, P., et al. (2010). Ca2+ hot spots on the mitochondrial surface are generated by $\mathrm{Ca} 2+$ mobilization from stores, but not by activation of store-operated $\mathrm{Ca} 2+$ channels. Mol. Cell 38, 280-290. doi: 10.1016/j.molcel.2010.04.003

Girodet, P. O., Ozier, A., Bara, I., Tunon de Lara, J. M., Marthan, R., and Berger, P. (2011). Airway remodeling in asthma: new mechanisms and potential for 
pharmacological intervention. Pharmacol. Ther. 130, 325-337. doi: 10.1016/j. pharmthera.2011.02.001

Glancy, B., and Balaban, R. S. (2012). Role of mitochondrial Ca2+ in the regulation of cellular energetics. Biochemistry 51, 2959-2973. doi: 10.1021/bi2018909

Gunter, T. E., Buntinas, L., Sparagna, G., Eliseev, R., and Gunter, K. (2000). Mitochondrial calcium transport: mechanisms and functions. Cell Calcium 28, 285-296. doi: 10.1054/ceca.2000.0168

Gunter, T. E., and Gunter, K. K. (2001). Uptake of calcium by mitochondria: transport and possible function. IUBMB Life 52, 197-204. doi: 10.1080/ 15216540152846000

Gunter, T. E., and Sheu, S. S. (2009). Characteristics and possible functions of mitochondrial $\mathrm{Ca}(2+)$ transport mechanisms. Biochim. Biophys. Acta 1787, 1291-1308. doi: 10.1016/j.bbabio.2008.12.011

Hai, T. W., Liu, F., Coukos, W. J., and Green, M. R. (1989). Transcription factor ATF cDNA clones: an extensive family of leucine zipper proteins able to selectively form DNA-binding heterodimers. Genes Dev. 3, 2083-2090. doi: 10.1101/gad.3.12b.2083

Hajnoczky, G., Csordas, G., Madesh, M., and Pacher, P. (2000). The machinery of local Ca2+ signalling between sarco-endoplasmic reticulum and mitochondria. J. Physiol. 529(Pt 1), 69-81. doi: 10.1111/j.1469-7793.2000.00069.x

Hajnoczky, G., Csordas, G., and Yi, M. (2002). Old players in a new role: mitochondria-associated membranes, VDAC, and ryanodine receptors as contributors to calcium signal propagation from endoplasmic reticulum to the mitochondria. Cell Calcium 32, 363-377. doi: 10.1016/s0143416002001872

Harding, H. P., Zhang, Y., and Ron, D. (1999). Protein translation and folding are coupled by an endoplasmic-reticulum-resident kinase. Nature 397, 271-274. doi: $10.1038 / 16729$

Hasnain, S. Z., Lourie, R., Das, I., Chen, A. C., and McGuckin, M. A. (2012). The interplay between endoplasmic reticulum stress and inflammation. Immunol. Cell Biol. 90, 260-270. doi: 10.1038/icb.2011.112

Hasnain, S. Z., Tauro, S., Das, I., Tong, H., Chen, A. C., Jeffery, P. L., et al. (2013). IL-10 promotes production of intestinal mucus by suppressing protein misfolding and endoplasmic reticulum stress in goblet cells. Gastroenterology 144 357.e9-368 e9. doi: 10.1053/j.gastro.2012.10.043

Heffner, J. E., and Repine, J. E. (1989). Pulmonary strategies of antioxidant defense. Am. Rev. Respir. Dis. 140, 531-554. doi: 10.1164/ajrccm/140.2.531

Hoffman, S. M., Tully, J. E., Nolin, J. D., Lahue, K. G., Goldman, D. H., Daphtary, N., et al. (2013). Endoplasmic reticulum stress mediates house dust miteinduced airway epithelial apoptosis and fibrosis. Respir. Res. 14:141. doi: 10. 1186/1465-9921-14-141

Hollien, J., and Weissman, J. S. (2006). Decay of endoplasmic reticulum-localized mRNAs during the unfolded protein response. Science 313, 104-107. doi: 10. 1126/science.1129631

Hu, H., Tian, M., Ding, C., and Yu, S. (2018). The C/EBP Homologous Protein (CHOP) Transcription Factor Functions in Endoplasmic Reticulum StressInduced Apoptosis and Microbial Infection. Front. Immunol. 9:3083. doi: 10. 3389/fimmu.2018.03083

Hung, Y. P., Albeck, J. G., Tantama, M., and Yellen, G. (2011). Imaging cytosolic $\mathrm{NADH}-\mathrm{NAD}(+)$ redox state with a genetically encoded fluorescent biosensor. Cell Metab. 14, 545-554. doi: 10.1016/j.cmet.2011.08.012

Jain, M., and Chandel, N. S. (2013). Rethinking antioxidants in the intensive care unit. Am .J. Respir. Crit. Care Med .188, 1283-1285. doi: 10.1164/rccm.201307$1380 \mathrm{CP}$

James, A. (2005). Airway remodeling in asthma. Curr. Opin. Pulm. Med. 11, 1-6. doi: 10.1097/01.mcp.0000146779.26339.d8

James, D. I., Parone, P. A., Mattenberger, Y., and Martinou, J. C. (2003). HFis1, a novel component of the mammalian mitochondrial fission machinery. J. Biol. Chem. 278, 36373-36379. doi: 10.1074/jbc.M303758200

Jeong, J. S., Kim, S. R., Cho, S. H., and Lee, Y. C. (2017). Endoplasmic Reticulum Stress and Allergic diseases. Curr. Allergy Asthma Rep. 17:82. doi: 10.1007/ s11882-017-0751-759

Jia, L., Delmotte, P., Aravamudan, B., Pabelick, C. M., Prakash, Y. S., and Sieck, G. C. (2013). Effects of the inflammatory cytokines TNF-alpha and IL-13 on stromal interaction molecule-1 aggregation in human airway smooth muscle intracellular $\mathrm{Ca}(2+)$ regulation. Am. J. Respir. Cell Mol. Biol. 49, 601-608. doi: 10.1165/rcmb.2013-0040OC

Jones, K. A., Lorenz, R. R., Prakash, Y. S., Sieck, G. C., and Warner, D. O. (1999a). ATP hydrolysis during contraction of permeabilized airway smooth muscle. Am. J. Physiol. 277, L334-L342. doi: 10.1152/ajplung.1999.277.2.L334
Jones, K. A., Perkins, W. J., Lorenz, R. R., Prakash, Y. S., Sieck, G. C., and Warner, D. O. (1999b). F-actin stabilization increases tension cost during contraction of permeabilized airway smooth muscle in dogs. J. Physiol. 519(Pt 2), 527-538. doi: 10.1111/j.1469-7793.1999.0527m.x

Joubert, P., and Hamid, Q. (2005). Role of airway smooth muscle in airway remodeling. J. Allergy Clin Immunol. 116, 713-716. doi: 10.1016/j.jaci.2005. 05.042

Katsumata, U., Miura, M., Ichinose, M., Kimura, K., Takahashi, T., Inoue, H., et al. (1990). Oxygen radicals produce airway constriction and hyperresponsiveness in anesthetized cats. Am. Rev. Respir. Dis. 141(5 Pt 1), 1158-1161. doi: 10.1164/ ajrccm/141.5_Pt_1.1158

Kim, S. R., Kim, D. I., Kang, M. R., Lee, K. S., Park, S. Y., Jeong, J. S., et al. (2013). Endoplasmic reticulum stress influences bronchial asthma pathogenesis by modulating nuclear factor kappaB activation. J. Allergy Clin. Immunol. 132, 1397-1408. doi: 10.1016/j.jaci.2013.08.041

Kim, S. R., and Lee, Y. C. (2015). Endoplasmic reticulum stress and the related signaling networks in severe asthma. Allergy Asthma Immunol. Res. 7, 106-117. doi: 10.4168/aair.2015.7.2.106

Kip, S. N., Hunter, L. W., Ren, Q., Harris, P. C., Somlo, S., Torres, V. E., et al. (2005). [Ca2+]i reduction increases cellular proliferation and apoptosis in vascular smooth muscle cells: relevance to the ADPKD phenotype. Circ. Res. 96, 873-880. doi: 10.1161/01.RES.0000163278.68142.8a

Koopman, W. J., Verkaart, S., Visch, H. J., van der Westhuizen, F. H., Murphy, M. P., van den Heuvel, L. W., et al. (2005a). Inhibition of complex I of the electron transport chain causes O2-. -mediated mitochondrial outgrowth. Am. J. Physiol. Cell Physiol. 288, C1440-C1450. doi: 10.1152/ajpcell.00607.2004

Koopman, W. J., Visch, H. J., Verkaart, S., van den Heuvel, L. W., Smeitink, J. A., and Willems, P. H. (2005b). Mitochondrial network complexity and pathological decrease in complex I activity are tightly correlated in isolated human complex I deficiency. Am. J. Physiol. Cell Physiol. 289, C881-C890. doi: 10.1152/ajpcell.00104.2005

Koopman, W. J., Visch, H. J., Smeitink, J. A., and Willems, P. H. (2006). Simultaneous quantitative measurement and automated analysis of mitochondrial morphology, mass, potential, and motility in living human skin fibroblasts. Cytometry A 69, 1-12. doi: 10.1002/cyto.a.20198

Kornmann, B. (2013). The molecular hug between the ER and the mitochondria. Curr. Opin. Cell Biol. 25, 443-448. doi: 10.1016/j.ceb.2013.02.010

Kornmann, B., and Walter, P. (2010). ERMES-mediated ER-mitochondria contacts: molecular hubs for the regulation of mitochondrial biology. J. Cell Sci. 123(Pt 9), 1389-1393. doi: 10.1242/jcs.058636

Kuhn, A. R., Schlauch, K., Lao, R., Halayko, A. J., Gerthoffer, W. T., and Singer, C. A. (2010). MicroRNA expression in human airway smooth muscle cells: role of miR-25 in regulation of airway smooth muscle phenotype. Am. J. Respir. Cell Mol. Biol. 42, 506-513. doi: 10.1165/rcmb.2009-0123OC

Lee, J. H., Johnson, P. R., Roth, M., Hunt, N. H., and Black, J. L. (2001). ERK activation and mitogenesis in human airway smooth muscle cells. Am. J. Physiol. Lung. Cell Mol. Physiol. 280, L1019-L1029. doi: 10.1152/ajplung.2001. 280.5.L1019

Lee, Y. J., Jeong, S. Y., Karbowski, M., Smith, C. L., and Youle, R. J. (2004). Roles of the mammalian mitochondrial fission and fusion mediators Fis1. Drp1 and Opal in apoptosis. Mol. Biol. Cell 15, 5001-5011. doi: 10.1091/mbc.e04-040294

Li, M., Baumeister, P., Roy, B., Phan, T., Foti, D., Luo, S., et al. (2000). ATF6 as a transcription activator of the endoplasmic reticulum stress element: thapsigargin stress-induced changes and synergistic interactions with NF-Y and YY1. Mol. Cell Biol. 20, 5096-5106. doi: 10.1128/mcb.20.14.5096-5106.2000

Liesa, M., Palacin, M., and Zorzano, A. (2009). Mitochondrial dynamics in mammalian health and disease. Physiol. Rev. 89, 799-845. doi: 10.1152/physrev. 00030.2008

Lipson, K. L., Fonseca, S. G., Ishigaki, S., Nguyen, L. X., Foss, E., Bortell, R., et al. (2006). Regulation of insulin biosynthesis in pancreatic beta cells by an endoplasmic reticulum-resident protein kinase IRE1. Cell Metab. 4, 245-254. doi: 10.1016/j.cmet.2006.07.007

Lipson, K. L., Ghosh, R., and Urano, F. (2008). The role of IRE1alpha in the degradation of insulin mRNA in pancreatic beta-cells. PLoS One 3:e1648. doi: 10.1371/journal.pone.0001648

Maack, C., and O’Rourke, B. (2007). Excitation-contraction coupling and mitochondrial energetics. Basic Res. Cardiol. 102, 369-392. doi: 10.1007/ s00395-007-0666-z 
Makhija, L., Krishnan, V., Rehman, R., Chakraborty, S., Maity, S., Mabalirajan, U., et al. (2014). Chemical chaperones mitigate experimental asthma by attenuating endoplasmic reticulum stress. Am. J. Respir. Cell Mol. Biol. 50, 923-931. doi: 10.1165/rcmb.2013-0320OC

Martino, M. B., Jones, L., Brighton, B., Ehre, C., Abdulah, L., Davis, C. W., et al. (2013). The ER stress transducer IRE1beta is required for airway epithelial mucin production. Mucosal. Immunol. 6, 639-654. doi: 10.1038/mi.2012.105

McLelland, G. L., Goiran, T., Yi, W., Dorval, G., Chen, C. X., Lauinger, N. D., et al. (2018). Mfn2 ubiquitination by PINK1/parkin gates the p97-dependent release of ER from mitochondria to drive mitophagy. Elife 7:e32866. doi: 10.7554/eLife. 32866

Miller, M., Rosenthal, P., Beppu, A., Mueller, J. L., Hoffman, H. M., Tam, A. B., et al. (2014). ORMDL3 transgenic mice have increased airway remodeling and airway responsiveness characteristic of asthma. J. Immunol. 192, 3475-3487. doi: 10.4049/jimmunol.1303047

Morris, G., Puri, B. K., Walder, K., Berk, M., Stubbs, B., Maes, M., et al. (2018). The endoplasmic reticulum stress response in neuroprogressive diseases: emerging pathophysiological role and translational implications. Mol. Neurobiol. 55, 8765-8787. doi: 10.1007/s12035-018-1028-1026

Movassagh, H., Shan, L., Halayko, A. J., Roth, M., Tamm, M., Chakir, J., et al. (2014). Neuronal chemorepellent Semaphorin 3E inhibits human airway smooth muscle cell proliferation and migration. J. Allergy Clin. Immunol. 133, 560-567. doi: 10.1016/j.jaci.2013.06.011

Munoz, J. P., Ivanova, S., Sanchez-Wandelmer, J., Martinez-Cristobal, P., Noguera, E., Sancho, A., et al. (2013). Mfn2 modulates the UPR and mitochondrial function via repression of PERK. Embo. J. 32, 2348-2361. doi: 10.1038/emboj. 2013.168

Munoz, J. P., and Zorzano, A. (2011). Endoplasmic reticulum stress enters a Nogo zone. Sci. Transl. Med. 3:88s26. doi: 10.1126/scitranslmed.3002708

Navid, F., and Colbert, R. A. (2017). Causes and consequences of endoplasmic reticulum stress in rheumatic disease. Nat. Rev. Rheumatol. 13, 25-40. doi: 10.1038/nrrheum.2016.192

Ngoh, G. A., Papanicolaou, K. N., and Walsh, K. (2012). Loss of mitofusin 2 promotes endoplasmic reticulum stress. J. Biol. Chem. 287, 20321-20332. doi: 10.1074/jbc.M112.359174

Nikawa, J., and Yamashita, S. (1992). IRE1 encodes a putative protein kinase containing a membrane-spanning domain and is required for inositol phototrophy in Saccharomyces cerevisiae. Mo.l Microbiol. 6, 1441-1446. doi: 10.1111/j.1365-2958.1992.tb00864.x

Pabelick, C. M., Prakash, Y. S., Kannan, M. S., and Sieck, G. C. (1999). Spatial and temporal aspects of calcium sparks in porcine tracheal smooth muscle cells. Am. J. Physiol. 277, L1018-L1025. doi: 10.1152/ajplung.1999.277.5.L1018

Palmer, C. S., Osellame, L. D., Stojanovski, D., and Ryan, M. T. (2011). The regulation of mitochondrial morphology: intricate mechanisms and dynamic machinery. Cell Signal. 23, 1534-1545. doi: 10.1016/j.cellsig.2011.05.021

Palmieri, L., Pardo, B., Lasorsa, F. M., del Arco, A., Kobayashi, K., Iijima, M., et al. (2001). Citrin and aralar1 are $\mathrm{Ca}(2+)$-stimulated aspartate/glutamate transporters in mitochondria. Embo. J. 20, 5060-5069. doi: 10.1093/emboj/20. 18.5060

Parekh, A. B. (2003). Mitochondrial regulation of intracellular Ca2+ signaling: more than just simple Ca2+ buffers. News Physiol. Sci. 18, 252-256. doi: 10. 1152/nips.01458.2003

Patergnani, S., Suski, J. M., Agnoletto, C., Bononi, A., Bonora, M., De Marchi, E., et al. (2011). Calcium signaling around Mitochondria Associated Membranes (MAMs). Cell Commun. Signal. 9:19. doi: 10.1186/1478-811X-9-19

Pathinayake, P. S., Hsu, A. C., Waters, D. W., Hansbro, P. M., Wood, L. G., and Wark, P. A. B. (2018). Understanding the Unfolded Protein Response in the Pathogenesis of Asthma. Front. Immunol. 9:175. doi: 10.3389/fimmu.2018. 00175

Peng, K., Yang, L., Wang, J., Ye, F., Dan, G., Zhao, Y., et al. (2017). The interaction of mitochondrial biogenesis and fission/fusion mediated by PGC-1alpha regulates rotenone-induced dopaminergic neurotoxicity. Mol. Neurobiol. 54, 3783-3797. doi: 10.1007/s12035-016-9944-9949

Prakash, Y. S. (2013). Airway smooth muscle in airway reactivity and remodeling: what have we learned? Am. J. Physiol. Lung. Cell Mol. Physiol. 305, L912-L933. doi: 10.1152/ajplung.00259.2013

Prakash, Y. S. (2016). Emerging concepts in smooth muscle contributions to airway structure and function: implications for health and disease. Am. J. Physiol. Lung. Cell Mol. Physiol. 311, L1113-L1140. doi: 10.1152/ajplung.00370.2016
Purohit, P. K., Edwards, R., Tokatlidis, K., and Saini, N. (2019). MiR-195 regulates mitochondrial function by targeting mitofusin-2 in breast cancer cells. RNA Biol. 16, 918-929. doi: 10.1080/15476286.2019.1600999

Raffaello, A., De Stefani, D., and Rizzuto, R. (2012). The mitochondrial Ca(2+) uniporter. Cell Calcium. 52, 16-21. doi: 10.1016/j.ceca.2012.04.006

Ranieri, M., Brajkovic, S., Riboldi, G., Ronchi, D., Rizzo, F., Bresolin, N., et al. (2013). Mitochondrial fusion proteins and human diseases. Neurol. Res. Int. 2013:293893. doi: $10.1155 / 2013 / 293893$

Raturi, A., and Simmen, T. (2013). Where the endoplasmic reticulum and the mitochondrion tie the knot: the mitochondria-associated membrane (MAM). Biochim. Biophys. Acta 1833, 213-224. doi: 10.1016/j.bbamcr.2012. 04.013

Rizzuto, R., Bernardi, P., and Pozzan, T. (2000). Mitochondria as all-round players of the calcium game. J. Physiol. 529(Pt 1), 37-47. doi: 10.1111/j.1469-7793.2000. 00037.x

Rizzuto, R., Marchi, S., Bonora, M., Aguiari, P., Bononi, A., De Stefani, D., et al. (2009). $\mathrm{Ca}(2+)$ transfer from the ER to mitochondria: when, how and why. Biochim. Biophys. Acta 1787, 1342-1351. doi: 10.1016/j.bbabio.2009.03.015

Rizzuto, R., and Pozzan, T. (2006). Microdomains of intracellular Ca2+: molecular determinants and functional consequences. Physiol. Rev. 86, 369-408. doi: 10. 1152/physrev.00004.2005

Romagnoli, A., Aguiari, P., De Stefani, D., Leo, S., Marchi, S., Rimessi, A., et al. (2007). Endoplasmic reticulum/mitochondria calcium cross-talk. Novartis Found. Symp. 287, 122-131. discussion 131-129.

Sano, R., and Reed, J. C. (2013). ER stress-induced cell death mechanisms. Biochim. Biophys. Acta 1833, 3460-3470. doi: 10.1016/j.bbamcr.2013.06.028

Sathish, V., Delmotte, P. F., Thompson, M. A., Pabelick, C. M., Sieck, G. C., and Prakash, Y. S. (2011). Sodium-calcium exchange in intracellular calcium handling of human airway smooth muscle. PLoS One 6:e23662. doi: 10.1371/ journal.pone.0023662

Sathish, V., Thompson, M. A., Bailey, J. P., Pabelick, C. M., Prakash, Y. S., and Sieck, G. C. (2009). Effect of proinflammatory cytokines on regulation of sarcoplasmic reticulum $\mathrm{Ca} 2+$ reuptake in human airway smooth muscle. Am. J. Physiol. Lung. Cell Mol. Physiol. 297, L26-L34. doi: 10.1152/ajplung.00026.2009

Schneeberger, M., Dietrich, M. O., Sebastian, D., Imbernon, M., Castano, C., Garcia, A., et al. (2013). Mitofusin 2 in POMC neurons connects ER stress with leptin resistance and energy imbalance. Cell 155, 172-187. doi: 10.1016/j.cell. 2013.09.003

Shanahan, C. M., and Furmanik, M. (2017). Endoplasmic reticulum stress in arterial smooth muscle cells: a novel regulator of vascular disease. Curr. Cardiol. Rev. 13, 94-105. doi: 10.2174/1573403X12666161014094738

Sheridan, C., and Martin, S. J. (2010). Mitochondrial fission/fusion dynamics and apoptosis. Mitochondrion 10, 640-648. doi: 10.1016/j.mito.2010.08.005

Siddesha, J. M., Nakada, E. M., Mihavics, B. R., Hoffman, S. M., Rattu, G. K., Chamberlain, N., et al. (2016). Effect of a chemical chaperone, tauroursodeoxycholic acid, on HDM-induced allergic airway disease. Am. J. Physiol. Lung. Cell Mol. Physiol. 310, L1243-L1259. doi: 10.1152/ajplung.00396. 2015

Sieck, G. C., Dogan, M., Young-Soo, H., Osorio Valencia, S., and Delmotte, P. (2019). Mechanisms underlying TNFalpha-induced enhancement of force generation in airway smooth muscle. Physiol. Rep. 7:e14220. doi: 10.14814/ phy2.14220

Sieck, G. C., Fournier, M., Prakash, Y. S., and Blanco, C. E. (1996). Myosin phenotype and SDH enzyme variability among motor unit fibers. J. Appl. Physiol. 80, 2179-2189. doi: 10.1152/jappl.1996.80.6.2179

Sieck, G. C., Han, Y. S., Prakash, Y. S., and Jones, K. A. (1998). Cross-bridge cycling kinetics, actomyosin ATPase activity and myosin heavy chain isoforms in skeletal and smooth respiratory muscles. Comp. Biochem. Physiol. B Biochem. Mol. Biol. 119, 435-450. doi: 10.1016/s0305-0491(98)00005-4

Sieck, G. C., Lewis, M. I., and Blanco, C. E. (1989). Effects of undernutrition on diaphragm fiber size, SDH activity, and fatigue resistance. J. Appl. Physiol. 66, 2196-2205. doi: 10.1152/jappl.1989.66.5.2196

Sieck, G. C., Sacks, R. D., Blanco, C. E., and Edgerton, V. R. (1986). SDH activity and cross-sectional area of muscle fibers in cat diaphragm. J. Appl. Physiol. 60, 1284-1292. doi: 10.1152/jappl.1986.60.4.1284

Sieck, G. C., White, T. A., Thompson, M. A., Pabelick, C. M., Wylam, M. E., and Prakash, Y. S. (2008). Regulation of store-operated Ca2+ entry by CD38 in human airway smooth muscle. Am. J. Physiol. Lung. Cell Mol. Physiol. 294, L378-L385. doi: 10.1152/ajplung.00394.2007 
Sieck, G. C., Zhan, W. Z., Prakash, Y. S., Daood, M. J., and Watchko, J. F. (1995). $\mathrm{SDH}$ and actomyosin ATPase activities of different fiber types in rat diaphragm muscle. J. Appl. Physiol. 79, 1629-1639. doi: 10.1152/jappl.1995.79.5.1629

Smirnova, E., Griparic, L., Shurland, D. L., and van der Bliek, A. M. (2001). Dynamin-related protein Drp1 is required for mitochondrial division in mammalian cells. Mol. Biol. Cell 12, 2245-2256. doi: 10.1091/mbc.12.8.2245

Song, Z., Ghochani, M., McCaffery, J. M., Frey, T. G., and Chan, D. C. (2009). Mitofusins and OPA1 mediate sequential steps in mitochondrial membrane fusion. Mol. Biol. Cell 20, 3525-3532. doi: 10.1091/mbc.E09-03-0252

Trian, T., Benard, G., Begueret, H., Rossignol, R., Girodet, P. O., Ghosh, D., et al. (2007). Bronchial smooth muscle remodeling involves calcium-dependent enhanced mitochondrial biogenesis in asthma. J. Exp. Med. 204, 3173-3181. doi: 10.1084/jem.20070956

Upton, J. P., Wang, L., Han, D., Wang, E. S., Huskey, N. E., Lim, L., et al. (2012). IRE1alpha cleaves select microRNAs during ER stress to derepress translation of proapoptotic Caspase-2. Science 338, 818-822. doi: 10.1126/science.1226191

van Vliet, A. R., Verfaillie, T., and Agostinis, P. (2014). New functions of mitochondria associated membranes in cellular signaling. Biochim. Biophys. Acta 1843, 2253-2262. doi: 10.1016/j.bbamcr.2014.03.009

Vandewynckel, Y. P., Laukens, D., Geerts, A., Bogaerts, E., Paridaens, A., Verhelst, $\mathrm{X}$., et al. (2013). The paradox of the unfolded protein response in cancer. Anticancer Res. 33, 4683-4694.

Vannuvel, K., Renard, P., Raes, M., and Arnould, T. (2013). Functional and morphological impact of ER stress on mitochondria. J. Cell Physiol. 228, 1802-1818. doi: $10.1002 /$ jcp. 24360

Verfaillie, T., Rubio, N., Garg, A. D., Bultynck, G., Rizzuto, R., Decuypere, J. P., et al. (2012). PERK is required at the ER-mitochondrial contact sites to convey apoptosis after ROS-based ER stress. Cell Death Differ. 19, 1880-1891. doi: $10.1038 /$ cdd.2012.74

White, T. A., Xue, A., Chini, E. N., Thompson, M., Sieck, G. C., and Wylam, M. E. (2006). Role of transient receptor potential C3 in TNF-alpha-enhanced calcium influx in human airway myocytes. Am. J. Respir. Cell Mol. Biol. 35, 243-251. doi: $10.1165 / \mathrm{rcmb} .2006-0003 \mathrm{OC}$

Wright, D. B., Trian, T., Siddiqui, S., Pascoe, C. D., Johnson, J. R., Dekkers, B. G., et al. (2013a). Phenotype modulation of airway smooth muscle in asthma. Pulm. Pharmacol. Ther. 26, 42-49. doi: 10.1016/j.pupt.2012.08.005
Wright, D. B., Trian, T., Siddiqui, S., Pascoe, C. D., Ojo, O. O., Johnson, J. R., et al. (2013b). Functional phenotype of airway myocytes from asthmatic airways. Pulm. Pharmacol. Ther. 26, 95-104. doi: 10.1016/j.pupt.2012.08.003

Yap, J., Chen, X., Delmotte, P., and Sieck, G. C. (2019). TNF $\alpha$ selectively activates the IRE1 $\alpha / \mathrm{XBP} 1$ endoplasmic reticulum stress pathway in human airway smooth muscle cells. Am. J. Physiol. Lung. Cell Mol. Physiol. (in press).

Yoshida, H., Matsui, T., Yamamoto, A., Okada, T., and Mori, K. (2001). XBP1 mRNA is induced by ATF6 and spliced by IRE1 in response to ER stress to produce a highly active transcription factor. Cell 107, 881-891. doi: 10.1016/ s0092-8674(01)00611-610

Youle, R. J., and van der Bliek, A. M. (2012). Mitochondrial fission, fusion, and stress. Science 337, 1062-1065. doi: 10.1126/science. 1219855

Yu, Z. H., Wang, Y. X., Song, Y., Lu, H. Z., Hou, L. N., Cui, Y. Y., et al. (2013). Upregulation of KCa3.1 promotes human airway smooth muscle cell phenotypic modulation. Pharmacol. Res. 77, 30-38. doi: 10.1016/j.phrs.2013.09.002

Zeeshan, H. M., Lee, G. H., Kim, H. R., and Chae, H. J. (2016). Endoplasmic reticulum stress and associated ROS. Int. J. Mol. Sci. 17:327. doi: 10.3390/ ijms 17030327

Zeng, L., Zampetaki, A., Margariti, A., Pepe, A. E., Alam, S., Martin, D., et al. (2009). Sustained activation of XBP1 splicing leads to endothelial apoptosis and atherosclerosis development in response to disturbed flow. Proc. Natl. Acad. Sci. U.. A. 106, 8326-8331. doi: 10.1073/pnas.0903197106

Zuo, L., Otenbaker, N. P., Rose, B. A., and Salisbury, K. S. (2013). Molecular mechanisms of reactive oxygen species-related pulmonary inflammation and asthma. Mol. Immunol. 56, 57-63. doi: 10.1016/j.molimm.2013.04.002

Conflict of Interest: The authors declare that the research was conducted in the absence of any commercial or financial relationships that could be construed as a potential conflict of interest.

Copyright $\odot 2020$ Delmotte and Sieck. This is an open-access article distributed under the terms of the Creative Commons Attribution License (CC BY). The use, distribution or reproduction in other forums is permitted, provided the original author(s) and the copyright owner(s) are credited and that the original publication in this journal is cited, in accordance with accepted academic practice. No use, distribution or reproduction is permitted which does not comply with these terms. 